\title{
Tubo-Ovarian Abscess with Bilateral Ovarian Endome- triotic Cysts Caused by Edwardsiella tarda Infection
}

\author{
Mastiar Endang Frida Siahaan ${ }^{1}$ and Andaru Dahesihdewi*2 \\ ${ }^{1}$ Charitas Hospital Palembang, Indonesia \\ ${ }^{2}$ Departement of Clinical Pathology and Laboratory Medicine, Faculty of Medicine Public Health, Indonesia
}

*Corresponding author: Andaru Dahesihdewi, Departement of Clinical Pathology and Laboratory Medicine, Faculty of Medicine

Public Health and Nursing, Indonesia

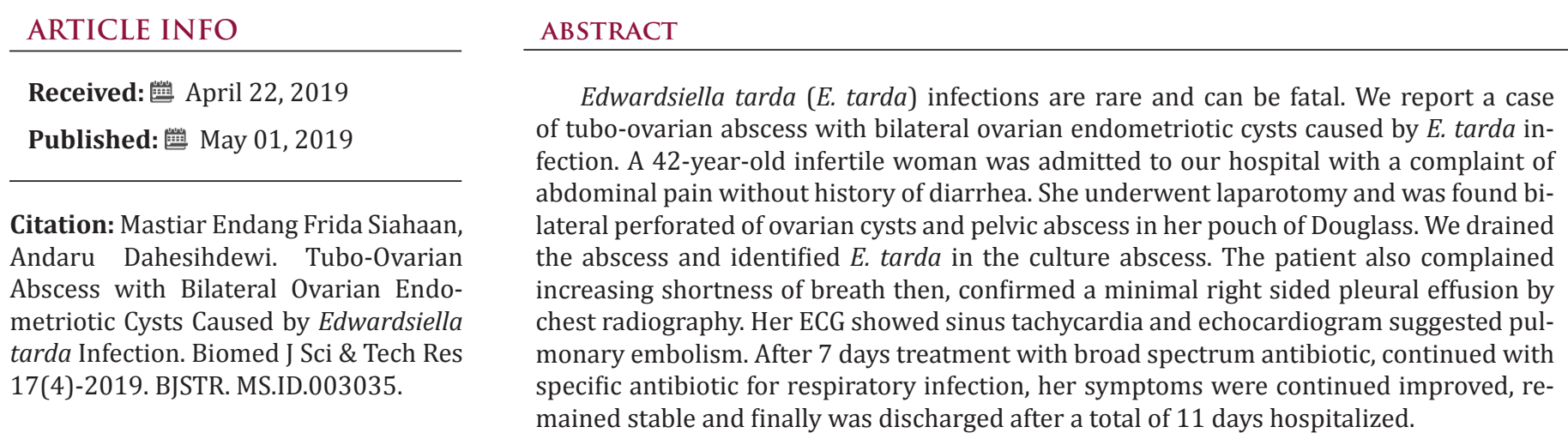

\section{Introduction}

Edwardsiella tarda (E. tarda) is a member of the family Enterobacteriaceae, a gram negative, motile, facultatively anaerobic rod-shaped bacteria. Edwardsiella infection are rare, the most common human infection is gastroenteritis. Here we report a case of a tubo-ovarian abscess with bilateral ovarian endometriotic cysts caused by E. tarda infection without any predisposing illnesses.

\section{Case Report}

A 42-year-old Indonesian woman patient was referred to our hospital with initial diagnosis of endometrial cysts. She was admitted for further investigation with a 2 days history of lower abdominal pain, vaginal discharge with acute onset shortness breath and generalized body weakness. Medical history was negative for any chronic illnesses. She was infertile for 16 years. On her physical examination the patient was alert and oriented with a $36.5^{\circ} \mathrm{C}$, pulse rate of 84 /minute, blood pressure of $110 / 80 \mathrm{~mm} \mathrm{Hg}$ and respiratory rate of $26 /$ minute. The oxygen saturation was $96 \%$ on room air. The cardiac and lungs exam was normal. Her abdomen was distended with moderate tenderness at lower quadrant area, no rebound tenderness and no palpated mass palpable. Liver and spleen were not palpable. Extremities were warm and well-perfused. Neck and the musculoskeletal examination were normal. The patient's pelvic examination revealed negative for cervical motion tenderness or adnexal masses.

Laboratory evaluation of blood study from initial hospital showed a normal white blood cell count of $6,700 / \mathrm{mm} 3$ with $92 \%$ of neutrophil, hemoglobin $11.9 \mathrm{~g} / \mathrm{dL}$, hematocrit $36 \%$ and platelet count was $335,000 / \mu \mathrm{L}$. Serum chemistry was normal. Urinalysis was blood and nitrite positive, 20-25 RBC/HPF and 15-20 WBC/ HPF. Urine pregnancy test was negative (Table 1). On admission, re-evaluation of blood study was normal and urine pregnancy test was negative. Ultrasound of abdomen and pelvis was performed, which showed free fluid in the pouch of Douglass reported as ectopic pregnancy. Patient was scheduled for emergency laparotomy with a diagnosis of ectopic pregnancy. Gentamycin $80 \mathrm{mg}$ was administered as an antimicrobial prophylaxis. Operative findings revealed bilateral perforated of ovarian cysts and pelvic abscess in the pouch of Douglass. The patient underwent bilateral salpingectomy and the specimen was sent for histopathologic examination. The pus was drained and sent for bacterial culture and antibiotic susceptibility testing. Postoperatively the patient was given empirically meropenem and metronidazole. 
Table 1: Initial Laboratory Report.

\begin{tabular}{|c|c|c|c|}
\hline Laboratory Test & Result & Normal Range & Unit \\
\hline $\mathrm{Hb}$ & 11.9 & $12.0-13.0$ & $\mathrm{~g} / \mathrm{dL}$ \\
\hline WBC & 6,700 & $5,000-10,000$ & cell/uL \\
\hline $\mathrm{RBC}$ & 4.4 & $4.0-5.0$ & million $/ \mathrm{mm}^{3}$ \\
\hline Haematocrite & 36 & $37-43$ & $\%$ \\
\hline Platelet & 335,000 & $150,000-400,000$ & cell/uL \\
\hline \multicolumn{4}{|l|}{ Differential count } \\
\hline Basophil & 0 & $0-1$ & $\%$ \\
\hline Eosinophil & 0 & 3-Jan & $\%$ \\
\hline Neutrophil & 92 & $50-70$ & $\%$ \\
\hline Lymphocyte & 5 & $20-40$ & $\%$ \\
\hline Monocyte & 3 & 8-Feb & $\%$ \\
\hline Blood Type & $\mathrm{A} /+$ & & \\
\hline Total Bilirubin & 1.2 & $0.2-1.2$ & $\mathrm{mg} / \mathrm{dL}$ \\
\hline AST & 9 & $<31$ & $\mathrm{U} / \mathrm{L}$ \\
\hline ALT & 8 & $<31$ & $\mathrm{U} / \mathrm{L}$ \\
\hline Blood glucose & 147 & $80-120$ & $\mathrm{mg} / \mathrm{dL}$ \\
\hline Bleeding Time & 3 & 6-Jan & minute \\
\hline Clotting Time & 6 & 7-May & minute \\
\hline Urine Pregnancy Test & Negative & & \\
\hline \multicolumn{4}{|l|}{ Urinalysis } \\
\hline Blood & 3 & Negative & \\
\hline Glucose & Negative & Negative & \\
\hline Protein & Negative & Negative & \\
\hline Bilirubin & Negative & Negative & \\
\hline Urobilirubin & Normal & Normal & \\
\hline $\mathrm{pH}$ & 5.5 & $6.5-7.0$ & \\
\hline Specific gravity & 1.025 & $1.003-1.30$ & \\
\hline Ketone & Negative & Negative & \\
\hline Nitrite & Positive & Negative & \\
\hline WBC sedimentation & $15-20$ & $0-5$ & /HPF \\
\hline RBC sedimentation & $20-25$ & $0-10$ & /HPF \\
\hline Crystal & - & & \\
\hline Cast & - & & \\
\hline Epithelial & 6-Apr & $0-2$ & $/ \mathrm{LPF}$ \\
\hline
\end{tabular}

The histopathologic examination revealed bilateral ovarian endometriotic cysts, multiple follicular cysts of ovary and bilateral salpingo-oophoritis. The culture result revealed only a heavy growth of Edwardsiella tarda (Figure 1a \& 1b). The E. tarda isolate was susceptible to all antibiotics tested (Table 2). The patient complained increasing shortness of breath then, one day after had undergone laparotomy. Her vital signs became as follows: body temperature 36.50C, blood pressure 110/90 mmHg, pulse 120 beats/min, respiratory rate 26 breaths/min, and oxygen saturation 98\%. Physical examination found vesicular breath with abnormal gallop sound which was confirmed as a minimal right sided pleural effusion by chest radiography. Her ECG showed sinus tachycardia and echocardiogram suggested pulmonary embolism. The patient was treated with 1 vial intravenous injection of furosemide. The result of D-dimer and Troponin-I test were $5.0 \mathrm{mg} / \mathrm{L}$ (normal range 0.1-0.3 $\mathrm{mg} / \mathrm{L}$ ) and $0.05 \mathrm{ng} / \mathrm{mL}$ (normal range $<0.01 \mathrm{ng} / \mathrm{mL}$ ), subsequently. The antibiotic switch to Azythromycin $1 \times 500 \mathrm{mg}$, after day-5, for 6 days later. The patient remained stable then and was discharge after for a total of 11 days hospitalized. 
Table 2: Susceptibility Test.

\begin{tabular}{|c|c|c|c|}
\hline Antibiotic & Result & Anbiotic & Result \\
\hline Ampicillin & S & Amikacin & S \\
\hline Ampicillin/Sulbactam & S & Gentamicin & S \\
\hline Piperacillin/Tazobactam & S & Tobramycin & S \\
\hline Cefalotin & S & Ciprofloxacin & S \\
\hline Cefoxitin & S & Levofloxacin & S \\
\hline Cefotaxime & S & Tetracycline & S \\
\hline Ceftazidime & S & Fosfomycin & S \\
\hline Cefepime & S & Trimetrophim/ Sulfamethoxazone & S \\
\hline Meropenem & S & \\
\hline
\end{tabular}

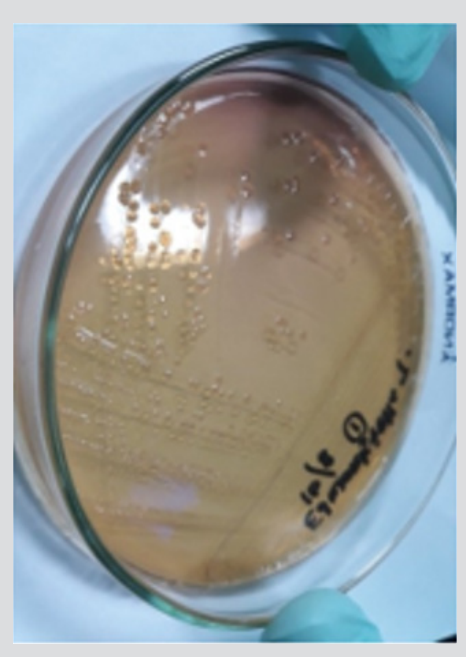

Figure 1a: Edwarsiella tarda colony in McConkey agar, after 24 incubation at $370 \mathrm{C}$.

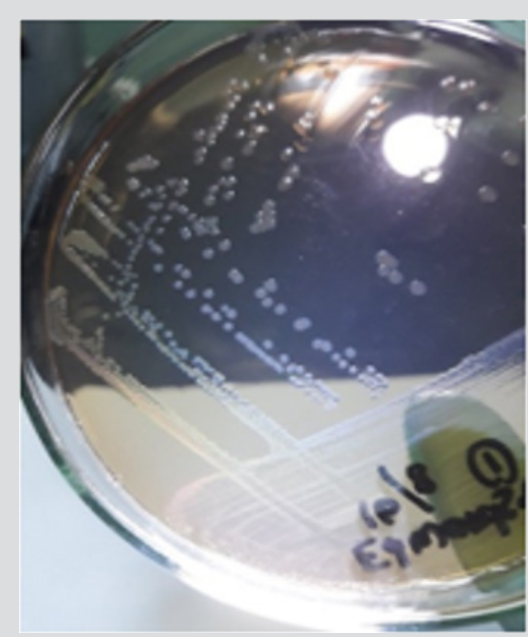

Figure 1b: The colony were small, transparent and punctate.

\section{Discussion}

Edwardsiella tarda is an anaerobic Gram-negative bacillus associated with freshwater environments and animal. Human infections caused by E. tarda are rare but has been reported cultured in human stool, blood, urine, CSF, abscess, peritoneal fluid and wounds.
In more than $80 \%$ of cases, the organism is cultured from stool specimens and is associated with gastrointestinal illness [1]. This organism, have been reported, can result in extraintestinal infections including soft- tissue infection, bacteremia, meningitis, cholecystitis, osteomyelitis, salpingitis and endocarditis. Extraintestinal infections are rare and very often associated with immune-compromised states [2]. The cases of gynecologic infection associated with E. tarda have been reported. Two women were reported with gynecologic infections that involved abscess formation and E. tarda was isolated in pure culture from a ruptured tubo-ovarian abscess [2]. A young woman with salpingitis and tubo-ovarian abscess related to colonization of the gastrointestinal tract was diagnosed after ingestion of raw fish [3].

The patient in our case report had not recently handled any wild animals or reptiles. She had no exposure to freshwater or saltwater environment, but she often ate 'pindang. 'Pindang' is a wellcooked South Sumatra cuisine made from fresh water fish such as patin fish. The patient in our case report experienced fever, abdominal pain but without diarrhea. In fact, we did not know the exact of E. tarda entry port in this patient. There was no previous report of infertility, effusion pleura and pulmonary emboli caused by E. tarda infection. Edwarsiella tarda is usually susceptible to a wide variety of antibiotics and therefore, nearly any approved drug can be used to combat the infection [4]. In our patient, the E. tarda isolate was susceptible to all antibiotics tested and patient was cured well.

\section{References}

1. Janda JM, Abbott SL, Kroske-Bystrom S, Cheung WK, Powers C, et al. (1991) Pathogenic properties of Edwardsiella species. J Clin Microbiol 29(9): 1997-2001.

2. Slaven EM, Lopez FA, Hart SM, Sanders CV (2001) Myonecrosis caused by Edwardsiella tarda: A case report and case series of extraintestinal $\mathrm{E}$. tarda infections. Clin Infect Dis 32(10): 1430-1433.

3. Pien FD, Jackson MT (1995) Tuboovarian abscess caused by Edwardsiella tarda. Am J Obsted Gynecol 173(3): 964-965.

4. Stock I, Wiedemann B (2001) Natural antibiotic susceptibilities of Edwardsiella tarda, E. ictaluri, and E. hoshinae. Antimicrob Agents Chemother 45(8): 2245- 2255 . 


\section{ISSN: 2574-1241}

DOI: 10.26717/BJSTR.2019.17.003035

Andaru Dahesihdewi. Biomed J Sci \& Tech Res

(C) This work is licensed under Creative

Submission Link: https://biomedres.us/submit-manuscript.php

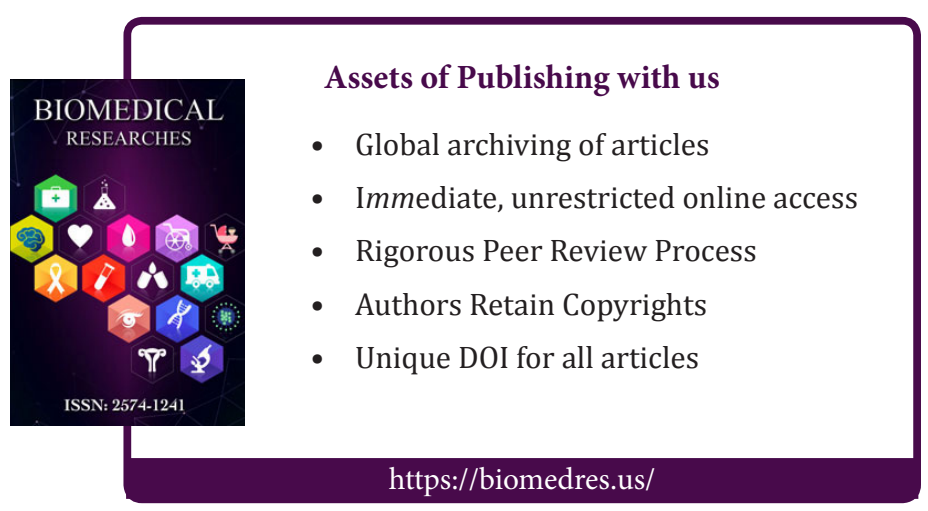

